\title{
“QUERO MARCAR MEU CORPO COM ALGO BOM": A TATUAGEM NA CONSTRUÇÃO DA SUBJETIVIDADE DE MULHERES FEMINISTAS
}

\author{
Hyldalice de Andrade ${ }^{1}$
}

Esta série de desenhos parte do encontro da tatuagem com a pesquisa etnográfica. Esse encontro é fruto da minha particular inserção no campo enquanto pesquisadora, tatuadora e militante. A pesquisa busca compreender, a partir de relatos de vida de jovens universitárias, como se produz a subjetividade de mulheres autoidentificadas como feministas. Ela se apoia, sobretudo, nas relações que construí ao longo da minha passagem pela militância feminista e estudantil universitária. Esse estudo, ainda em curso, vem sendo feito na cidade do Rio de Janeiro desde 2018, ano em que iniciei o mestrado. Foi também nesse período que me inseri na tatuagem e comecei a atender pessoas da minha rede de relações próximas. Nesse sentido, minha passagem pela militância possibilitou não só a criação dos vínculos necessários à pesquisa etnográfica, como também de relações de amizade e solidariedade com minhas interlocutoras. E foi precisamente o caráter singular de tais relações que permitiu e delineou os encontros entre a pesquisa e a tatuagem.

"Quero marcar meu corpo com algo bom" - afirmação de uma das interlocutoras dita no momento dialógico anterior à realização da tatuagem - exprime o valor moral atribuído à produção expressiva, voluntária e reflexiva de marcas corporais que, ao mesmo tempo, dramatizam e constroem uma biografia. A tatuagem, que nas últimas décadas vem se constituindo, cada vez mais, como uma peça artística, passa a ser valorizada por aquilo que é capaz de expressar sobre a pessoa tatuada. A elaboração do desenho, mais que uma busca meramente estética, é concebida na maioria dos casos como uma exteriorização da interioridade da pessoa a ser tatuada. É nesse sentido que a tatuagem emerge como um caminho de produção da subjetividade (Pérez, 2006) ou como um "recurso auto-bio-gráfico" nos termos de Ferreira (2011). Desse modo, em vista da centralidade de ícones relacionados ao feminino, à luta feminista e à memória de Marielle Franco na elaboração dos desenhos, considero que essas jovens buscam na tatuagem um recurso de construção de si de um modo intimamente relacionado ao

1 Universidade do Estado do Rio de Janeiro, Brasil. E-mail: marques.hylda@gmail.com ORCID: https://orcid.org/0000-0002-9057-0765 
feminismo. E, não sem motivo, elegeram a mim - uma tatuadora feminista - para a produção de tais marcas.

Este trabalho realizou um percurso singular em termos do modo como o desenho e a pesquisa etnográfica foram relacionados. Ele não foi composto por desenhos de observação feitos num caderno ao longo do trabalho de campo, mas sim produzidos posteriormente com auxílio da minha memória e das fotos que registraram os processos de tatuagem. Nesse sentido, não foi o "caderno" que simbolizou a ponte entre o desenho e a etnografia como sugere Kuschnir (2016), mas, no campo, foi o próprio corpo das interlocutoras que emergiu como o suporte de uma iconografia feminista. Portanto, nessa pesquisa, o desenho e a etnografia se encontraram em dois momentos: primeiro, na feitura das tatuagens e, depois, na produção dos desenhos. Aqui, exponho cinco das tatuagens que realizei nos últimos dois anos. Cada tatuagem foi representada em seu momento de feitura e em sua forma final, na pele da tatuada. Dentre as cinco, duas foram realizadas nos próprios quartos das interlocutoras tatuadas; as outras três, no estúdio de tatuagem feminista ao qual me associei durante esse percurso (a Casa Xottta, inaugurada em 2019 no Centro do Rio de Janeiro). Algumas dessas ilustrações foram feitas com papel e tinta nanquim antes de receberem um acabamento digital; outras foram, desde o princípio, criadas digitalmente.

\section{REFERÊNCIAS}

FERREIRA, Vitor Sérgio. Tatuar o corpo jovem hoje: rito de passagem ou ritual de impasse? Vivência: Revista de Antropologia, Natal, n. 36, p. 137-156, 2011.

KUSCHNIR, Karina. A antropologia pelo desenho: experiências visuais e etnográficas. Cadernos de Arte e Antropologia, Salvador, v. 5, n. 2, p. 5-13, 2016.

PÉREZ, Andrea L. A identidade à flor da pele: etnografia da prática da tatuagem na contemporaneidade. Mana, Rio de Janeiro, v.12, n. 1, p. 179-206, 2006.

Recebido: 30/04/2020

Aprovado: $08 / 12 / 2020$ 

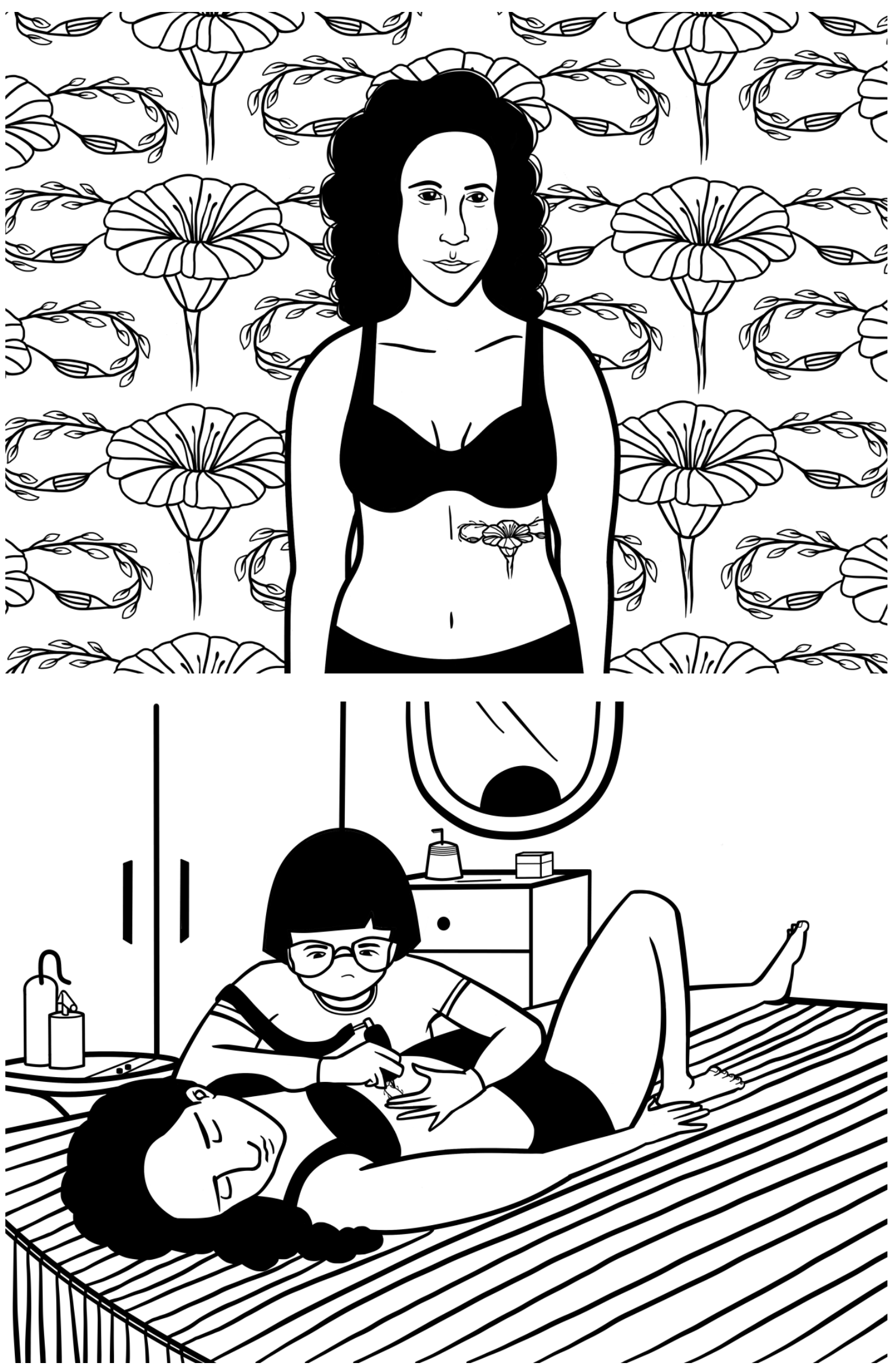

Imagens 1 e 2: A tatuada com seu "florútero" e a realização da tatuagem em seu quarto. 

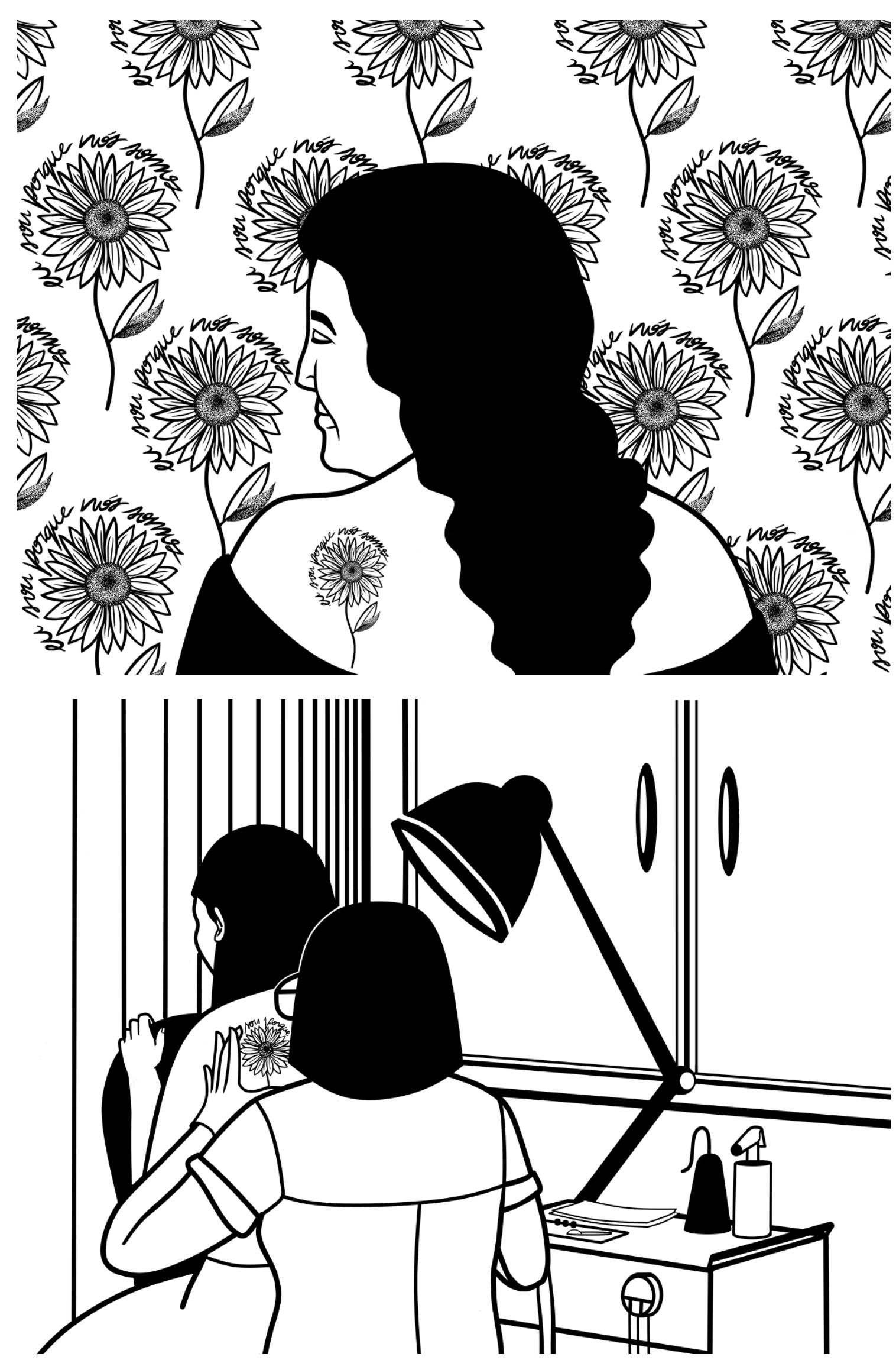

Imagens 3 e 4: A tatuada, e a tatuagem feita em homenagem à Marielle Franco, e sua produção no estúdio. 

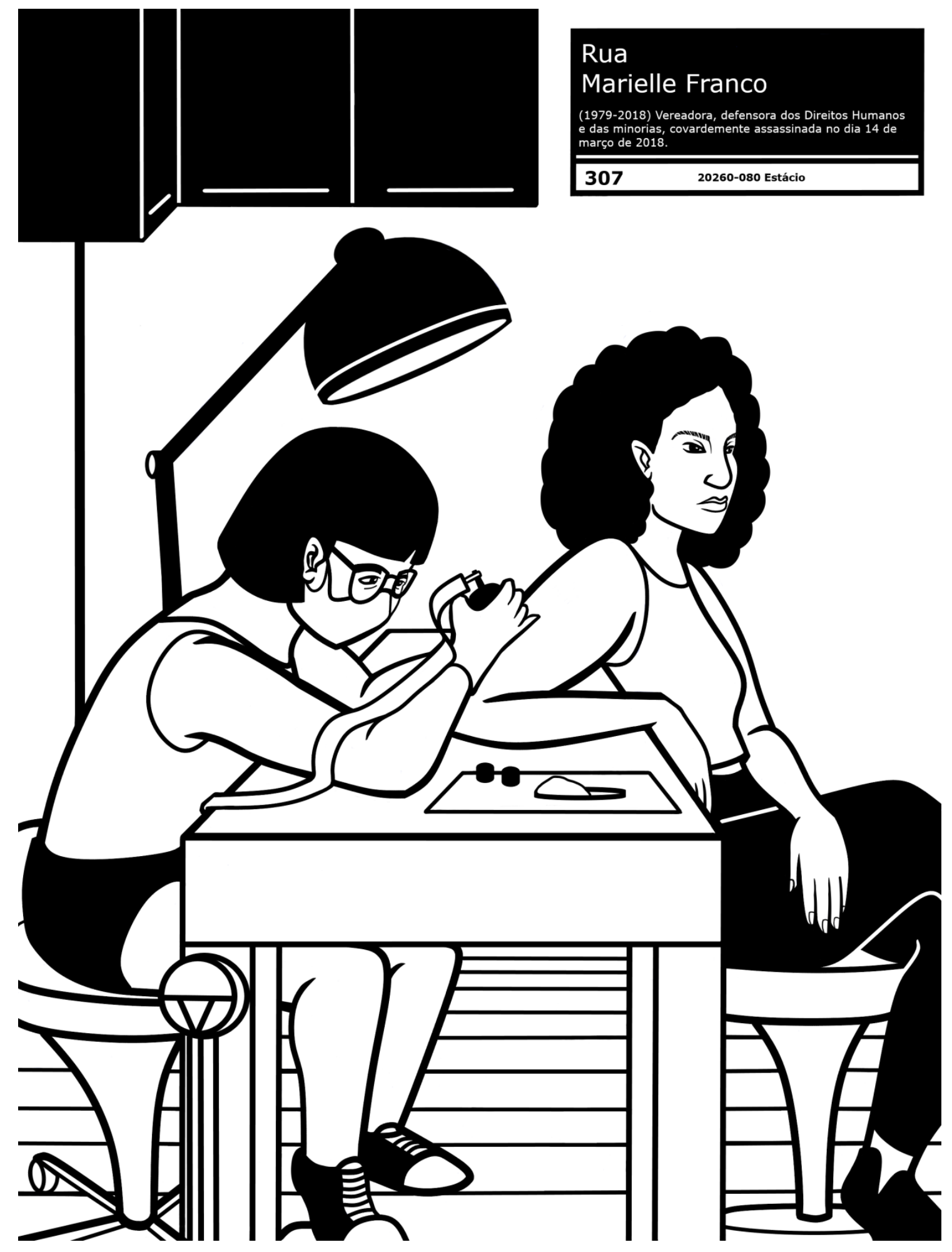

Imagem 5: Realização da tatuagem no estúdio. 


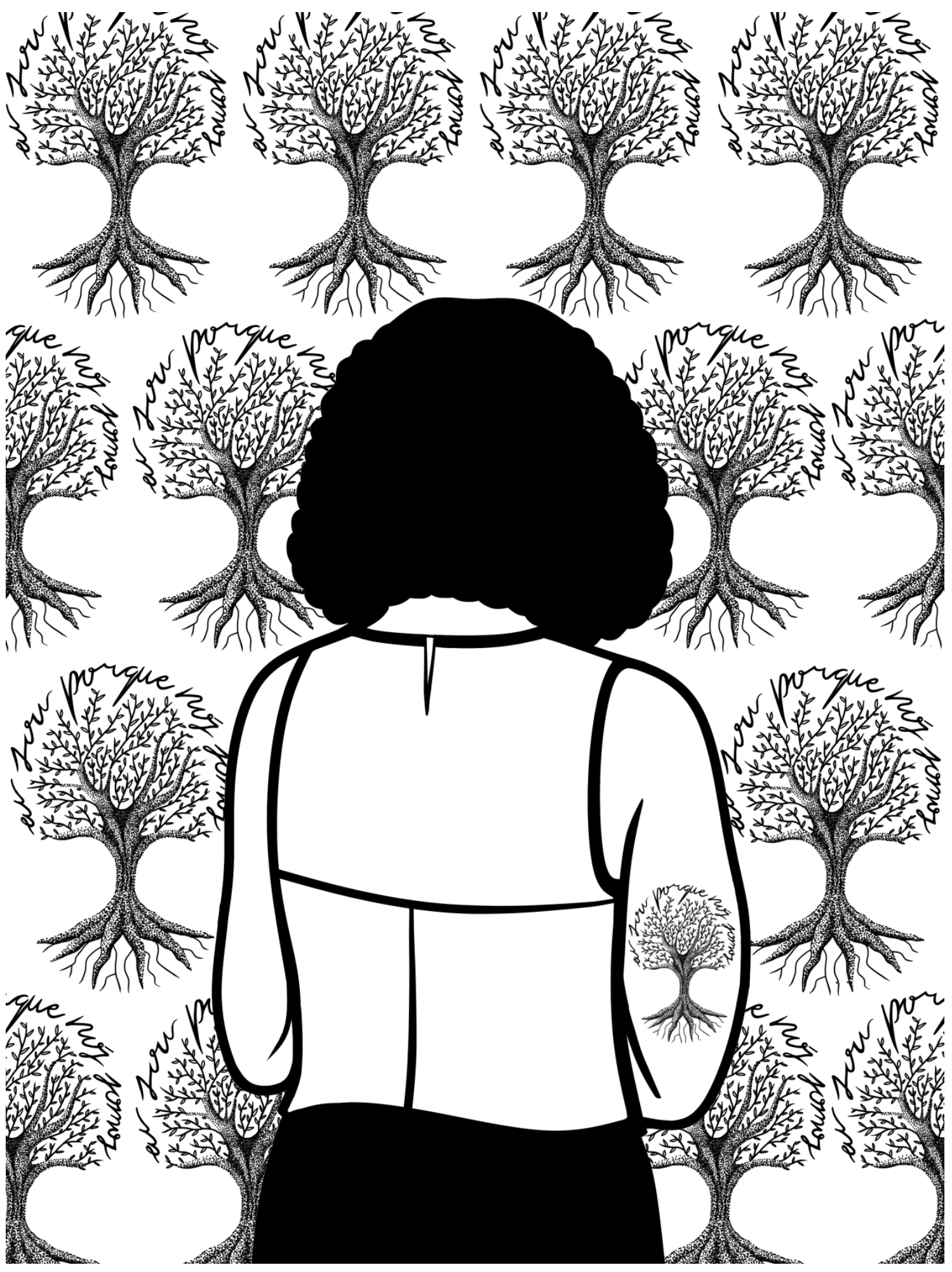

Imagem 6: Resultado do processo representado na imagem anterior. As combinações do slogan da candidatura de Marielle Franco ("eu sou porque nós somos") com referências ao semear, às raízes e ao florescer foram recorrentes nas construções dessas homenagens. 
"Quero marcar meu corpo com algo bom": a tatuagem na construção da subjetividade de mulheres feministas

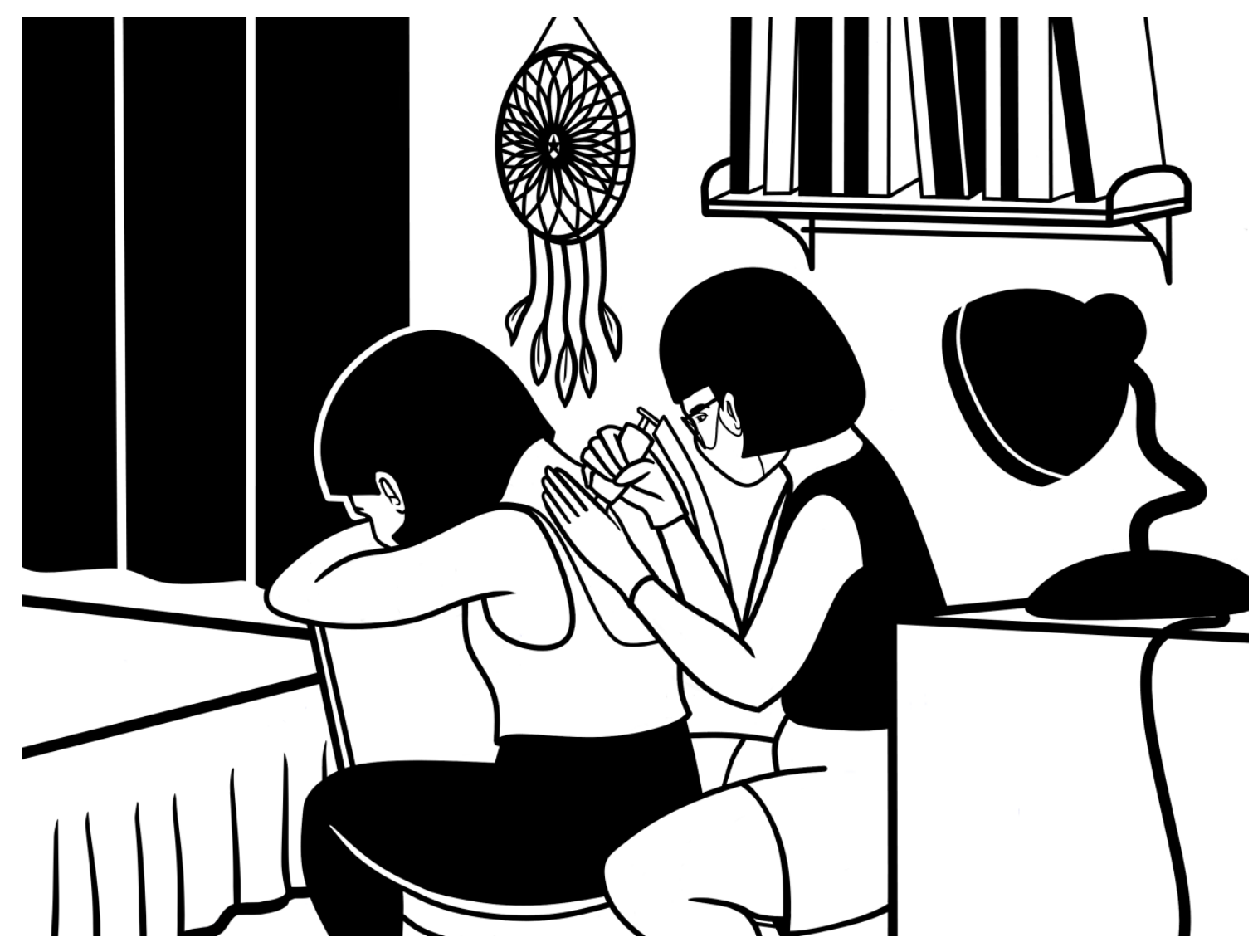




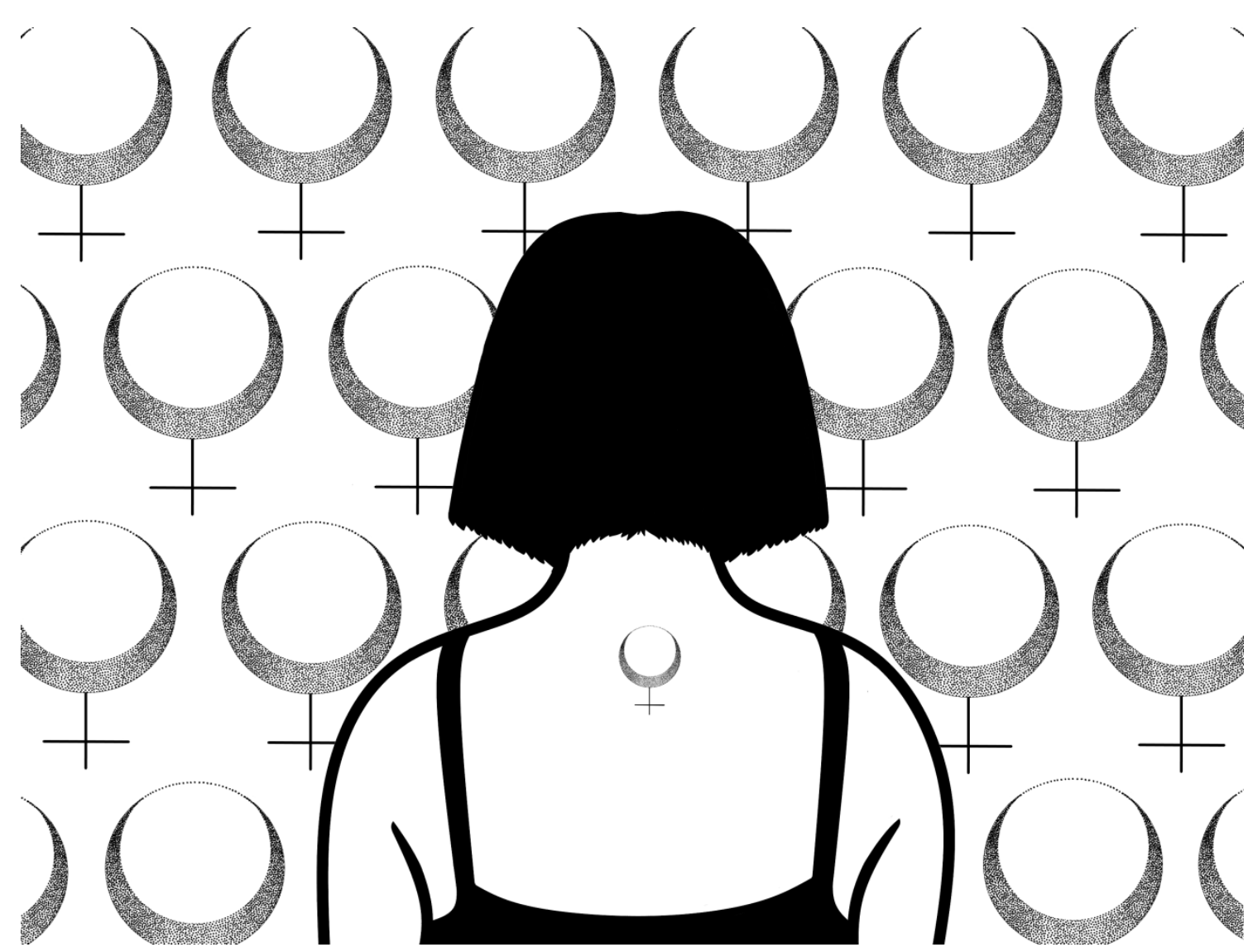

Imagem 7 e 8: Feitura da tatuagem no quarto da interlocutora e seu resultado. Essa tatuagem foi realizada no dia 08 de março de 2018, quando completou um ano desde que a tatuada fora vítima de agressão por parte do ex-namorado. Ela é autora da frase que dá título ao trabalho. 


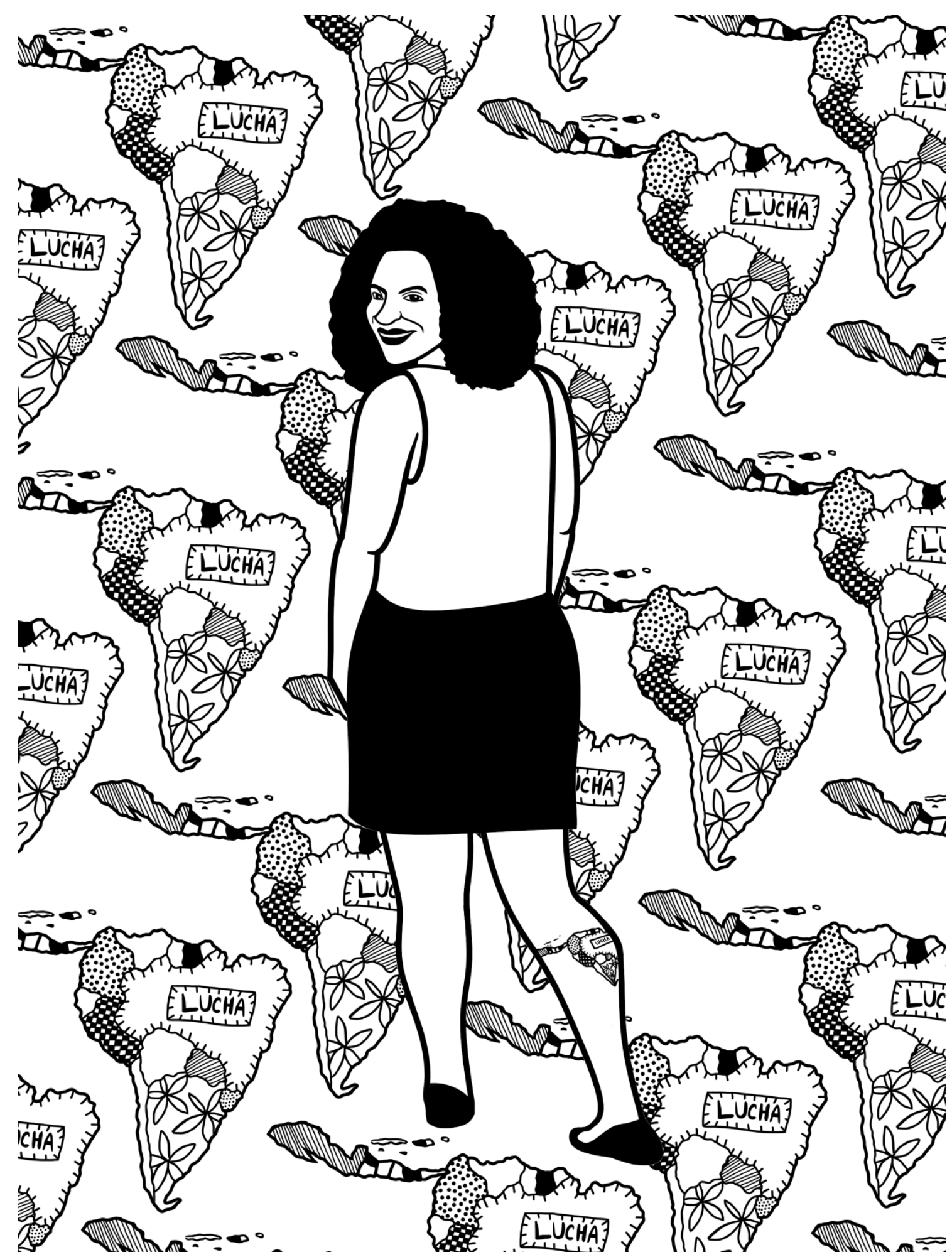

Imagem 9: Resultado da tatuagem que remete às lutas latinoamericanas. O desenho foi inspirado na técnica de bordado das arpilleras, oriunda do Chile, fonte de subsistência e de denúncia das violações do regime militar de Pinochet. A mesma técnica é utilizada atualmente por mulheres do Movimento de Atingidos por Barragens (MAB). 


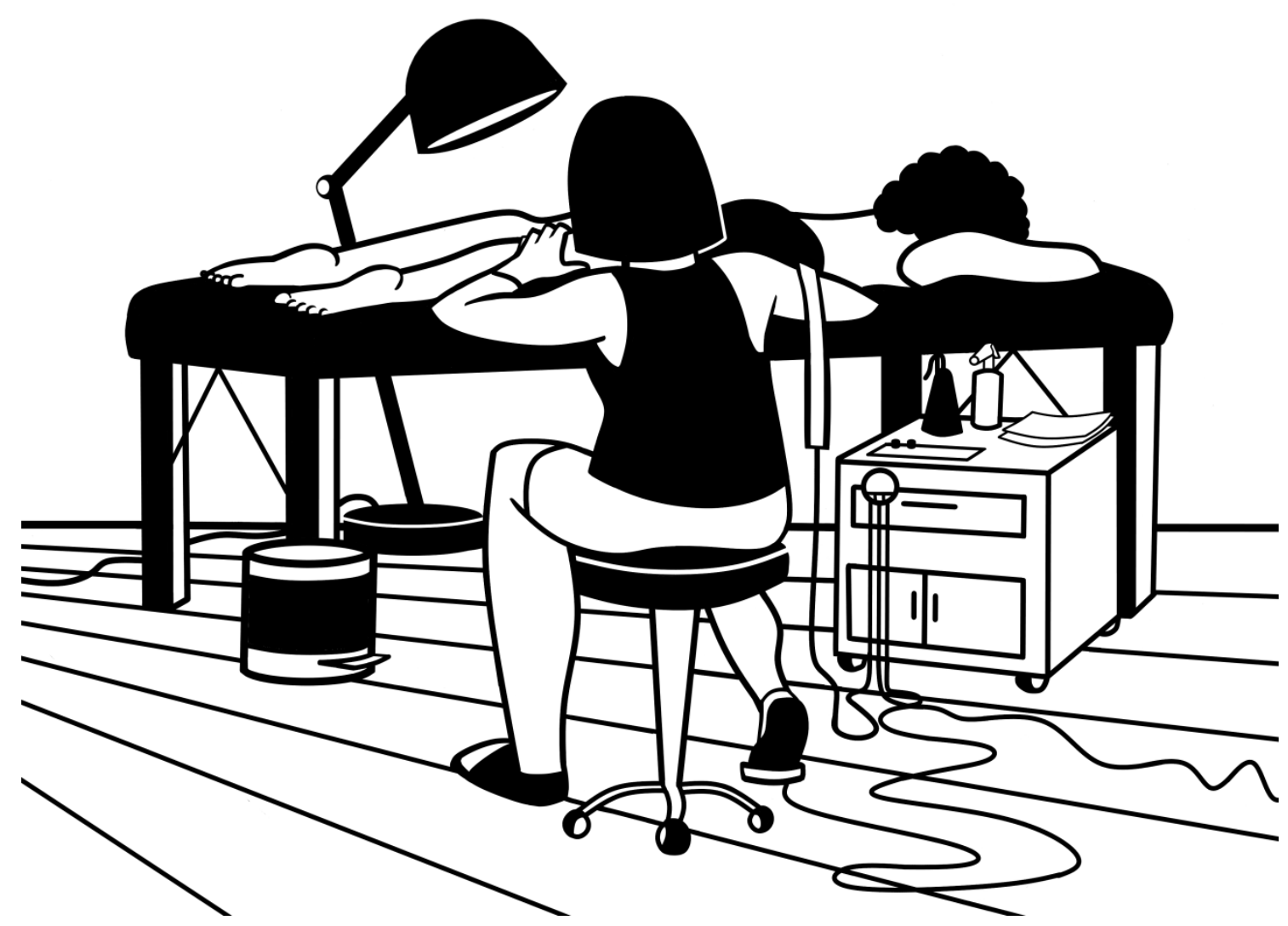

Imagem 10: Processo de realização da tatuagem referida na imagem anterior, feita no estúdio da Casa Xottta. 